\title{
Softball Referee Quality based on Reviewed Anxiety Level
}

\author{
Y Firmansyah*, N Kusmaedi, Komarudin Komarudin \\ Program Studi Pendidikan Olahraga, Sekolah Pascasarjana \\ Universitas Pendidikan Indonesia \\ Bandung, Indonesia \\ *yogi.firmansyah@student.upi.edu
}

\begin{abstract}
The purpose of this study is to examine the relationship with the performance of softball referees based on qualification levels. The research methods used correlational methods. The research sample was determined based on purposive sampling during softball that occurred in three championships. The data collected from the anxiety test and performance of national qualification softball $A$ and beginner, and processed using the Kolmogorov-Smirnov Test. The results show that there is no statistically significant relationship on performance is a national qualification softball $A$. That is, the available qualification level has a significant relationship with operating statistics of $76.7 \%$.
\end{abstract}

Keywords—softball; anxiety level

\section{INTRODUCTION}

The role of the referee in leading a sports competition is very important, the number of demands given, making the referee must have various supports to be able to display good performance. In addition to having to master the understanding of the rules in the sport that is involved, the referee must also pay attention to the physical aspects and psychological factors [1].

One psychological factor that plays an important role in the success of a person displays good performance, namely anxiety. Anxiety is a complex emotion with many intellectual, physiological, and behavioral symptoms, often associated with stress or excitement [2]. Anxiety is defined as a feeling of anxiety and tension caused by the environment or surrounding expectations related to arousal [3], so that it can affect a person's performance [4]. Then one's performance can also be influenced by anxiety caused by the perspective of mind understanding based on behavior [5]. Therefore, anxiety is predicted to be a factor that influences sports performance. Among the many forms of psychiatric problems that occur, psychiatrists agree that anxiety is one of the greatest human problems.

Many assumptions that in order to achieve the best performance for sports people must be able to eliminate perceived anxiety. Though anxiety is a basic human feeling since their existence on earth [6], it cannot be eliminated but can be controlled [7]. Controlling anxiety during a sports situation will make performance more optimal, because actually anxiety can have a positive effect, only at certain limits and after that anxiety can negatively affect the athlete's achievement [8]. Thus, excessive anxiety and continuing to increase will cause disruption in sports performance.

Some studies have shown that anxiety has a positive linear relationship with the performance of basketball players [9], then the level of anxiety also shows a positive relationship with the performance of elite and non-elite athletes in Malaysia [10]. This shows that the anxiety felt by an athlete is affected by what he displays on the field.

The relationship between anxiety and the level of performance in various sports has been the subject of many studies [11], but most focus on the performance of athletes. Whereas in the world of sports, sports players involved in the field are not only athletes who compete, so that high-level psychology skills are not only needed by athletes but also by referees in competitive sports [12]. This is also constrained by only a small amount of research that has been carried out on referees. In addition, most of the research on referees has been based on qualitative evaluation [13].

Theoretically anxiety has a relationship with good sports performance against athletes, possibly also against referees in leading matches softball. This study is intended to answer the question of how the quality referee's softball of national qualifying $\mathrm{A}$ and beginners when leading a match in terms of their level of anxiety?

\section{METHOD}

\section{A. Participants}

The sample was determined based on purposive sampling as many as 16 people in referee's softball who served on the National Procurator Softball Men's and Telkom University CUP 2018. The sample was divided into 8 national A qualification referees and 8 beginner qualified referees.

\section{B. Procedurs}

The research method used is a correlational method [14]. This study lasted for two consecutive championships from 28 March to 15 April 2018. 


\section{Instruments}

Instruments used to measure anxiety are the Competitive State Anxiety Inventory (CSAI-2) [15]. Meanwhile, to measure the performance of the referee, the softball instrument used is a form of assessment of the performance of referee's softball issued by the PB Perbasasi federation [16]. The value on this anxiety scale is different from the variable performance of the referee who has a positive value. That is, the higher the score on the referee's performance scale, the better the results. While on the anxiety scale, the value is negative, meaning that the lower the value of anxiety, the better the results obtained, and the higher the value of anxiety, the less good the results.

\section{Analysis}

Data processing was carried out using the KolmogorovSmirnov test. Testing is done between anxiety scores and referee performance in accordance with their qualifications.

\section{RESULTS AND DISCUSSION}

TABLE I. RESULTS OF THE TEST OF THE RELATIONSHIP BETWEEN ANXIETY AND THE PERFORMANCE OFREFEREES SOFTBALL

\begin{tabular}{|l|l|l|l|}
\hline \multicolumn{1}{|c|}{ Qualification } & \multicolumn{1}{c|}{ R } & \multicolumn{1}{c|}{ R Square } & Sig. \\
\hline National A & -0.648 & 0.420 & 0.073 \\
\hline Beginner & $-0.876^{* *}$ & 0.767 & 0.004 \\
\hline
\end{tabular}

Based on table 1 on the Pearson correlation between anxiety and the performance referee softball of national qualifying A produces a number of $r=-0.648$. This shows the level of correlation between anxiety with the performance referee softball of national qualifying A is strong. While the significance value is 0.073 , because the value $p$ is greater than $0.05(p=0.073>0.05)$ it can be concluded that there is no significant relationship between anxiety and the performance referee softball of national qualification A.

Then the Pearson correlation between anxiety and the performance of referee softball the beginner qualifying generates the number $r=-0.876$. This shows the level of correlation between anxiety and the performance of the referee softball beginner is very strong. While the significance value is 0.004 , because the value $p$ is smaller than $0.05(p=0.004$ $<0.05)$ it can be concluded that there is a significant relationship between anxiety and the performance of referee softball the beginner qualifying, with a contribution value of $76.7 \%$.

There is something interesting from the explanation of the results of the calculation above, that referee softball National Qualification A does not have a statistically significant relationship between anxiety with the performance of the referee in leading matches softball. Whereas the beginner qualification softball referee has a very strong relationship. From these results it can be said that the anxiety felt by a referee softball at low or high levels still has a negative impact on its performance. But if the anxiety felt to be at a moderate level will make optimal performance. Moderate on the explanation means that it is at the right level, not too high or low [17]. Then a high level of competitive anxiety, both cognitive and somatic, can have a major impact on performance [18]. It identifies that the higher the anxiety felt by a referee a softball adverse, it will have impact on their performance when leading the match. That way it can be said that someone who can control the anxiety in him will have a good impact on his performance.

In the context of sports, especially a referee, when feeling anxious when he is in charge of leading a match, it does not mean that he must eliminate the anxiety. As already explained that anxiety is a basic feeling that has existed since humans were born, so it cannot be eliminated. The most likely is to control how perceived anxiety does not become a burden or obstacle to display the best performance. Controlling anxiety during a sports situation will make performance more optimal, because if you feel too much anxiety, fear, or stress it might cause disruption in performance in sports [7].

In referee's softball, various situations may cause anxiety in him as appointed to lead important matches or assignments in the final match, the situation will make the referee depressed and unable to do the best so that it affects his performance. That the more important events experienced, the higher the level of stress that is felt and the more someone feels in an uncertain state, the higher the anxiety and stress that will be experienced [19]. Therefore, for a referee it should be able to control the anxiety he feels and transfer it into positive energy so that it does not adversely affect his performance.

When looking at the level of the referee level softball, the qualification of referee softball National $\mathrm{A}$ is the highest qualification of the referee. On this basis the level that is owned indicates that the referee has more experience than the level of the referee below. With a lot of experience at various levels of competition it should not be a problem in the face of a match. They should be better prepared than anyone, can act as leaders, and can master the on going match. But the level of anxiety and intensity of self-confidence needed to produce activation of optimal performance and arousal states has been shown to vary among sports players, including referees [20].

The specific form of anxiety varies greatly depending on a series of self-changes such as the perception of the training situation, experience, ability to anticipate, personal expectations, the results of which lead to anxiety, specific behavior in the case of sports competitions [21]. From this explanation, it can be said that referees who have a high level / qualification are not necessarily able to control the anxiety that comes to him, it depends on the atmosphere in the referee. Whereas for referee softball the beginner qualifying, anxiety has a very strong relationship. This indicates that referees at the beginner level have good control of the anxiety they feel. This is because the referees at that level will be more careful when acting in deciding an event, sometimes they ignore all kinds of disturbances that occur in the field so that they can display good performance.

\section{CONCLUSION}

Anxiety is a phenomenon that is experienced by everyone from time to time, as well as in the context of sports for a referee softball. Anxiety has always been one of the fundamental problems when facing a match, a high level of 
anxiety makes a referee unable to show his best performance and will have a bad impact when making a decision. Anxiety can be detrimental to a referee while on duty if anxiety is felt to be very high, but anxiety can greatly help the referee because anxiety is an alarm for someone to be more careful in doing a job. Therefore, a referee softball must be able to control the anxiety he feels, turning it into positive energy, so that he will be better prepared when leading the match. This psychological factor has very strong theoretical reasons so it will be good if it continues to be researched and developed to get more validation of the referee's qualifications.

\section{REFERENCES}

[1] B.W. Brewer, Sport Psychology. Springfield: Willey-Blackwell, 2009.

[2] D. Jurko, "Relations Between Competitive Anxiety and Self-Confidence States and Situational Achievement of Elite European Junior Female Volleyball Players," Acta Kinesiologica, vol. 7, no. 1, pp. 55-59, 2013.

[3] B. Khodayari, A. Saiiari and Y. Dehghani, "Comparison Relation between Mental Skills with Sport Anxiety in Sprint and Endurance Runners," Procedia - Social and Behavioral Sciences, vol. 30, pp. 22802284, 2011.

[4] D.H. Han, J.H. Kim, Y.S. Lee, S.J. Bae, S.J. Bae, H.J. Kim, M.Y. Sim, Y.H. Sung and I.K. Lyoo, "Influence of Temprament and Anxiety on Athletic Performance," Journal of Sports Science and Medicine, vol. 5, pp. 381-389, 2006

[5] M. Humara, "The Relationship Between Anxiety and Performance: A Cognitive-Behavioral Perspective," Athletic Insight, vol. 1, no. 2, pp. 114, 1999.

[6] E. Kayaa, İ. Sarib, E. Tolukana and M. Gülle, "Examination of Trait Anxiety Levels of Physical Education and Sports Students (Ibrahim Cecen University Case)," Procedia - Social and Behavioral Sciences, vol. 152, pp. 399-402, 2014

[7] J. Pijpers, R.R. Oudejans, F. Holsheimer and F.C. Bakker, "AnxietyPerformance Relationships in Climbing: A Process-Oriented Approach," Psychology of Sport and Exercise, vol. 4, pp. 283-304, 2003.

[8] Harsono, Coaching dan Aspek-aspek Psikologi dalam Coaching. Bandung: CV. Irwan, 1988
[9] A. Bridges and B. Knight, The Role of Cognitive and Somatic Anxiety in Athletic Performance. Hanover College: Independent Study, 2005.

[10] V.A. Parnabas, Y. Mahamood and J. Parnabas, "he Relationship between Cognitive and Somatic Anxiety on Performance of StudentAthletes of Universiti Malaysia Perlis (UNIMAP)," Sport and Art, vol. 1, no. 3, pp. 61-66, 2013.

[11] M. Radochoński, W.J. Cynarski, L. Perenc and L. Siorek-Maślanka, "Competitive Anxiety and Coping Strategies in Young Martial Arts and Track and Field Athletes," Journal of Human Kinetics, vol. 27, pp. 180189,2011

[12] M. Nishigai and N. Kida, "Evaluating Psychological Skills of Japanese Amateur Baseball Referees," Advances in Physical Education, vol. 8, pp. 31-34, 2018

[13] K. Murakami, D. Hirata and S. Sato, "Psychological Characteristics of Top Referees: Based on Results of Interviews with Referees," Research Journal of Sports Performance, vol. 8, pp. 76-87, 2015

[14] J.R. Fraenkel, N.E. Wallen and H.H. Hyun, How to Design and Evaluate Research in Education. New York: McGraw-Hill, 2012.

[15] R. Martens, R.S. Vealey and D. Burton, Competitive Anxiety in Sport, Champaing. IL: Human Kinetics, 1990.

[16] T. Winardi, Official Rules of Softball 2014 - 2017. Jakarta: PB Perbasasi, 2015.

[17] H. Kristjánsdóttira, A.V. Erlingsdóttira, G. Sveinssonb and J.M. Saavedra, "Psychological Skills, Mental Toughness and Anxiety in Elite Handball Players," Personality and Individual Differences, vol. 134, pp. 125-130, 2018.

[18] M.R. Wilson, G. Wood and S.J. Vine, "Anxiety, Attentional Control, and Performance Impairment in Penalty Kicks," Journal of Sport and Exercise Psychology, vol. 31, no. 6, pp. 761-775, 2009.

[19] R. Weinberg and D. Gould, Foundations of Sport and Exercise Psychology (Sixth Edition). United State of America: Human Kinetics, 2015.

[20] R. Mullen, A. Lane and S. Hanton, "Anxiety Symptom Interpretation in High-Anxious, Defensive High-Anxious, Low-Anxious and Repressor Sport Performers," Routledge Taylor \& Francis Group, vol. 22, no. 1, pp. 91-100, 2009.

[21] V. Cojocaru, S. Tüdös, R. Predoiu, E. Colită and D. Colită, "Study Regarding the Impact of Trait Anxiety on Intersegmental Coordination and Topographical Memory in Junior Football Players," Procedia Social and Behavioral Sciences, vol. 187, pp. 124-129, 2015. 